\title{
Antecedents of Job Crafting Behavior within Organizations: The Role of Personal Resources, Job Resources and Perceived Opportunities to Craft in Employees Proactive Behavior
}

\author{
Jessica van Wingerden \\ Erasmus University Rotterdam \\ Institute of Psychology, Rotterdam, The Netherlands
}

Rob F Poell

Tilburg University, Department of Human Resource Studies, The Netherlands

Received: June 11, 2019 Accepted: July 2, 2019 Online published: July 15, 2019

doi:10.5296/ijhrs.v9i3.14908ＵRL: https://doi.org/10.5296/ijhrs.v9i3.14908

\begin{abstract}
This study examines the impact of personal resources and job resources on employees' perceived opportunities to craft and job crafting behavior. Based on research following the Job Demands and Resources (JD-R) theory, we hypothesize that personal resources (i.e., resilience and self-efficacy) and job resources (i.e., developmental opportunities and feedback) have a positive relationship with employees' perceived opportunities to craft and actual job crafting behavior in multiple and interrelated ways. We collected data among employees working in various organizations and occupations in The Netherlands $(N=810)$, and tested the hypothesized multiple mediation model using structural equation modelling (SEM) analyses. The outcomes of the study increase our knowledge of the factors affecting job crafting behavior within organizations - including employee perceptions (perceived opportunities to craft), employee characteristics (personal resources), and work characteristics (job resources). Combining these antecedents, this study may help to better understand and to stimulate job crafting behavior at work.
\end{abstract}

Keywords: personal resources, job resources, perceived opportunities to craft, job crafting, structural equation modelling 


\section{Introduction}

Wrzesniewski and Dutton (2001) introduced the concept of job crafting in their seminal article "Crafting a job: Revisioning employees as active crafters of their work". Employees who craft their jobs proactively align their talents, strengths, and interests, with their work environment. Over the last two decades, researchers in the field of work and organizational psychology have linked job crafting to a wide variety of positive outcomes, such as work engagement (e.g., Tims, Bakker, \& Derks, 2012; Van Wingerden, Bakker, \& Derks, 2017a; Van Wingerden, Van der Stoep, \& Poell, 2018), organizational commitment (e.g., Ghitulescu, 2007), and employability (e.g., Petrou, Demerouti, Peeters, Schaufeli, \& Hetland, 2012). Due to these merits, scholars and practitioners are highly motivated to gain a better understanding of the antecedents of employees job crafting behavior at work.

Recently, studies have demonstrated that job crafting behavior is related to an employee's regulatory focus (Brenninkmeijer \& Hekkert-Koning, 2015), and to perceived opportunities to craft (Van Wingerden, Derks, Bakker, \& Dorenbosch, 2013; Van Wingerden \& Poell, 2017). More precisely, these studies made clear that employees craft their jobs when they experience opportunities to do so. For example, when employees experienced that proactively changing their direct work environment was constrained by management or organizational culture, they were less likely to craft their jobs (Van Wingerden et al., 2013). Extant research indicates that job crafting behavior depends on the characteristics of both the employee and the work environment (Bakker, Tims \& Derks, 2012; Bipp \& Demerouti, 2015; Gordon, Demerouti, Le Blanc, \& Bipp, 2015; Petrou et al., 2012; Van Wingerden \& Niks, 2017; Van Wingerden \& Poell, 2017). Hitherto, however, it remains largely unclear how exactly antecedents of job crafting such as job resources, personal resources and perceived opportunities to craft are related and how they affect job crafting behavior in combination.

The main objective of this study is therefore to explore and test the relationships between multiple predictors - including employee perceptions (perceived opportunities to craft), employee characteristics (personal resources), and work characteristics (job resources) - and their combined relationships with job crafting behavior of employees within contemporary organizations. Drawing from decades of research on the Job Demands and Resources (JD-R) theory (Bakker \& Demerouti, 2014), we test a model of antecedents of job crafting behavior. This model may support scholars to better conceptualize and position their work on job crafting behavior, and may help practitioners to stimulate job crafting behavior and subsequently engagement, commitment, and employability within organizations (Ghitulescu, 2007; Petrou et al., 2012; Van Wingerden, Bakker \& Derks, 2017a).

\section{Theoretical Background}

\subsection{Job Crafting: The Self-Initiated Change Behaviors in the Workplace}

Job crafting can be defined as employees' self-initiated changes aimed at aligning their job and work environments with their own preferences, motives, and passions (Wrzesniewski \& Dutton, 2001). By crafting their job, employees actually alter the boundaries of their job. Wrzesniewski and Dutton distinguished three forms of job crafting behavior. Changing the 
physical or temporal boundaries of the task is known as task crafting. Redefining interpersonal relationships at work is known as relational crafting. Changing one's cognitions on the meaning of the job is known as cognitive crafting. Modifications in all these areas may result in lasting changes in the design of the job (LePine \& Van Dyne, 1998). All in all, through job crafting employees are able to proactively influence their work and their work environment.

In line with JD-R theory (Bakker \& Demerouti, 2014), Tims et al. (2012) operationalized job crafting behavior by distinguishing four types of observable behavior; 1 . increasing social job resources (e.g., asking for coaching from one's direct manager), 2. increasing structural job resources (e.g., creating opportunities to learn on the job), 3. increasing challenging job demands (e.g., taking the initiative to participate in the organization's works council), and 4. decreasing hindering job demands (e.g., taking extra breaks during the workday and/or avoiding difficult tasks) (Tims et al., 2012). As earlier studies on decreasing hindering job demands have shown mixed results, this type of behavior will not be included in the present study (e.g., Petrou et al., 2012; Tims, Bakker, Derks, \& Van Rhenen, 2013; Van Wingerden, Bakker, \& Derks, 2017b).

The job crafting approaches by Wrzesniewski and Dutton (2001) and by Tims et al. (2012) both suggest that job crafting reflects self-directed employee initiative to alter the direct work environment. They differ, however, with regard to the cognitive element that is included in the conceptualization of job crafting by Wrzesniewski and Dutton (2001). While Wrzesniewski and Dutton argued that employees are able to alter how they view their work, and in this way are able to see their work in a more meaningful and positive way, Tims, Bakker \& Derks (2012) focused purely on observable behaviors influencing the work environment (job demands and job resources), in line with the JD-R theory. In the present study we will follow the approach of Tims and colleagues, since it is a well-validated and often utilized scale to accurately measure job crafting behavior. Both approaches, however, agree on the positive effects that come from job crafting behavior; for example, work engagement (Bakker, Tims, \& Derks, 2012; Van Wingerden et al., 2017a), basic needs satisfaction (Van Wingerden et al., 2017a), and performance (Leana, Appelbaum, \& Shevchuk, 2009; Van Wingerden et al., 2017b), which make it clear that it is worthwhile to dive deeper into the factors that precede job crafting behavior of employees. In the current study, perceived opportunities to craft, job resources, and personal resources will be investigated as possible antecedents of job crafting.

\subsection{Perceived Opportunities to Craft and Job Resources}

Previous studies have shown that job crafting behavior depends on the opportunities that employees perceive to actually craft their work environment (Van Wingerden \& Niks, 2017; Van Wingerden \& Poell, 2017; Wrzesniewski, 2003; Wrzesniewski \& Dutton, 2001). Perceived opportunities to craft is defined as employees' perceptions regarding their opportunities to proactively optimize their own work environment (Van Wingerden \& Poell, 2017). In recent years, multiple studies have consistently shown that employees who perceive opportunities to craft their work are more likely to actually do so (Van Wingerden et al., 2013; 
Van Wingerden \& Poell, 2017). In a qualitative study by Van Wingerden et al. (2013), employees who participated in a job crafting intervention mentioned that their perceived opportunities to craft their job determined whether or not they actually engaged in this type of job crafting behavior. When they did not perceive opportunities to do so, for example through constraining managerial behavior, behavioral patterns, or organizational culture, they did not engage in job crafting behavior. Thus, this study implies a relationship between employees' perceived opportunities to craft and their job crafting behavior.

Whether or not employees perceive opportunities to craft their work, in turn, largely depends on how they assess their work characteristics (Van Wingerden \& Poell, 2018). JD-R theory (Bakker \& Demerouti, 2014) helps us to understand the impact of work characteristics on how employees think and behave at work. One basic assumption of JD-R theory is that work is characterized by job demands (e.g., work pressure, role conflict, and emotionally demanding situations) and job resources (e.g., autonomy, feedback, and opportunities to learn and grow). Job demands are aspects of the job that require employees' energy and thus come with certain costs (Demerouti, Bakker, Nachreiner, \& Schaufeli, 2001), while job resources are aspects of the job that provide an employee with energy and are functional for achieving work objectives.

Contrary to job demands, job resources start a motivational process that encourages employees to achieve their objectives (Boyd, Bakker, Pignata, Winefield, Gillespie and Stough, 2011). Since the main objective of this study is to examine factors that may stimulate employees' job crafting behavior behavior, we will foremost and primarily focus on employees' job resources. Specifically, we focus on feedback and opportunities for professional development, since these two resources have been incessantly linked with employee motivation, basic need satisfaction and pro-active behavior (Hakanen, Bakker \& Schaufeli, 2006; Van den Broeck, Vansteenkiste, De Witte, Soenens \& Lens, 2010; Van den Broeck, Vansteenkiste, De Witte \& Lens, 2008; Van Wingerden et al., 2017b). Feedback from manager, customers, or colleagues gives employees information about their performance at work, which increases the likelihood of being successful in achieving work goals (Bakker \& Bal, 2010), and through opportunities for professional development employees are able to learn and apply new knowledge and skills that will improve their performance on the job (Colbert, Brown, Choi, \& Thomas, 2008).

We argue that employees' perceived opportunities to craft and thus their job crafting behavior depend on their assessment of these specific job resources. For instance, when managers provide employees with positive feedback on their earlier job crafting behavior, they simultaneously and positively affect how employees perceive the opportunities to craft (see also Wrzesniewski, 2003). Furthermore, a recent study of Van Wingerden and Niks (2017) showed that an employee's perceived opportunities to craft depend on the opportunities for professional development at work as perceived by the employee. All in all, we thus first argue that job resources can positively affect job crafting behavior via perceived opportunities to craft.

Hypotheses 1: Job resources (i.e., feedback and developmental opportunities) are 
positively related with job crafting behavior via perceived opportunities to craft.

\subsection{Personal Resources and Job Resources}

Earlier studies have demonstrated that job crafting behavior depends not only on external factors (i.e., job resources), but also on factors lying within the employee (Van Wingerden \& Niks, 2017; Wrzesniewski, 2003; Wrzesniewski \& Dutton, 2001). These personal resources defined as aspects of the self that are commonly associated with resilience and individuals' sense of ability to control and impact their environment successfully (Hobfoll, Johnson, Ennis, \& Jackson, 2003) - have been recognized as crucial for an individual's work-related well-being (Luthans \& Youssef, 2007), as they stimulate personal development and help people achieve their goals (Xanthopoulou, Bakker, Demerouti, \& Schaufeli, 2009). Job crafting, for example, has also been linked with personal characteristics of the employee, like approach temperament (Bipp \& Demerouti, 2015), and proactive personality (Bakker et al., 2012). Examples of personal resources include resilience and self-efficacy (Luthans, Youssef, $\&$ Avolio, 2007). Based on the aforementioned studies, we argue that personal resources play a crucial part in the process that precedes job crafting behavior.

For example, the personal resource self-efficacy - defined as the "belief in one's capabilities to organize and execute the course of action required to produce given attainments" (Bandura, 1996, p. 3) - provides employees with confidence in their own ability to achieve their objectives, leading to an increased likelihood that they volunteer for new projects at work. In this way, self-efficacy can influence job crafting behavior. In a similar vein, resilience helps employees cope with and adapt to risk and / or adversity (Masten, 2001). At work, resilience is defined as the "positive psychological capacity to rebound, to 'bounce back' from adversity, uncertainty, conflict, failure, or even positive change, progress and increased responsibility" (Luthans, 2002, p. 702). Therefore, we argue that employees who are resilient might be better able to cope with the difficulties that come with crafting their job and subsequently are more likely to succeed in job crafting behavior. A study by Van Wingerden, Derks, and Bakker (2017c), revealed support for this assumption. In their study, participants' personal resources (self-efficacy and resilience) were positively related to their job crafting behavior, highlighting the importance of these personal resources in predicting job crafting behavior.

Furthermore, as job resources and personal resources are positively related (Bakker \& Demerouti, 2014; Xanthopoulou, et al., 2009; Xanthopoulou, Bakker, Demerouti, \& Schaufeli, 2007), we also expect an indirect relationship between job resources and job crafting behavior via personal resources. For example, increased feedback and information (job resources) help employees to gain a better understanding of their work, which help them to make better choices at work (e.g., Ashford, Blatt, \& VandeWalle, 2003), and subsequently influence the confidence in their own ability to achieve their objectives.. As this is the essence of self-efficacy (Bandura, 1977; Gist \& Mitchell 1992), we expect that feedback, as well as developmental opportunities, increases the self-efficacy beliefs of an employee. This perceived self-efficacy in turn stimulates human agency (Bandura, 1982), and in a similar vein the level of job crafting behavior of employees. All in all, we thus hypothesize that job resources (i.e., feedback and developmental opportunities) and job crafting behavior are 
positively related via personal resources (i.e., self-efficacy and resilience).

Hypotheses 2: Job resources (i.e., feedback and developmental opportunities) are positively related with job crafting behavior via personal resources (i.e., self-efficacy and resilience).

\subsection{Towards an Integral Model of Job Crafting Antecedents}

In the sections above we have outlined two ways through which job resources and job crafting behavior are related; via perceived opportunities to craft and via personal resources. A mixed-method intervention study by Van Wingerden et al. (2017c), combining qualitative and quantitative research methods, demonstrated the intricate connections among these constructs. In their study three different interventions were tested; 1 . an intervention aimed at increasing personal resources, 2.an intervention aimed at enhancing job crafting behavior and 3. an intervention aimed at enhancing both personal resources and job crafting behavior. The participants of the third intervention (aimed at increasing both personal resources and job crafting behavior) stated that by first working on their personal resources they felt able to change their work environment and experienced they had opportunities to do so. This study demonstrated the potential importance of personal resources, such as self-efficacy and resilience, and their interaction with perceived opportunities to craft. Therefore, we expect that personal resources affect job crafting behavior via changes in employees' perceived opportunities to craft. Lastly, as job resources are predictors of personal resources, we argue that job resources are also related to job crafting behavior via personal resources first and perceived opportunities to craft second.

All in all, we have laid down a model of multiple antecedents of job crafting behavior including employee perceptions (perceived opportunities to craft), employee characteristics (personal resources), and work characteristics (job resources). This model postulates how job resources and job crafting behavior are related in multiple ways; 1) via perceived opportunities to craft, and 2) via personal resources. In the previous subsection we have presented an argument for the existence of a third relationship; via personal resources and subsequently perceived opportunities to craft. Following this argument we finish by including this last relationship between job resources and job crafting in our conceptual model. This leads to the final hypothesis, which completes our model of job crafting antecedents (see Figure 1) that we intend to test in the current paper. Thereby it is important to note that all these antecedents are in multiple ways related and that combined they predict the level of job crafting behavior the best.

Hypothesis 3: Job resources (i.e., feedback and developmental opportunities) are positively related with job crafting behavior via personal resources (i.e., self-efficacy and resilience), and subsequently via perceived opportunities to craft. 


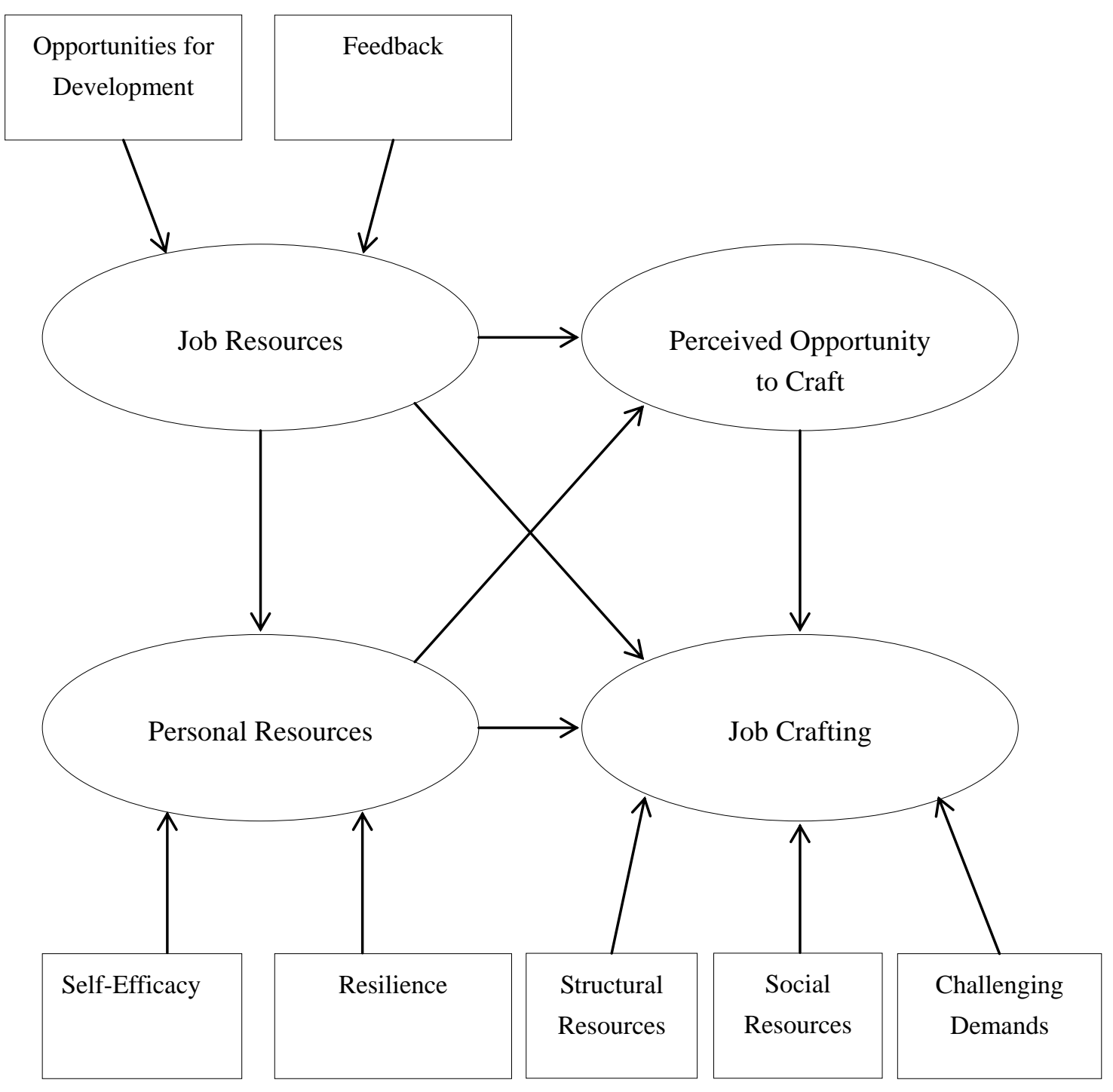

Figure 1. The Proposed Model

\section{Method}

\subsection{Design, Participants and Procedure}

\section{Design}

In this study, we used a quantitative, cross-sectional, survey-based design. Data for this study was collected via an online survey. A announcement of the study was posted on the website of a well-known Dutch career development website, and also shared via various social media channels (i.e. Facebook, Twitter and LinkedIn). Thus, data was collected from a diverse population to increase the heterogeneity of the participants, which facilitates generalization of the research findings (Demerouti \& Rispens, 2014). The study announcement contained a link, through which participants were able to read an introduction of the study and to start the survey. The questionnaire was available on the website for five weeks. Participants did not receive a monetary compensation for their participation, and they. filled in an informed consent form. 
Participants

The sample consisted of 810 professionals working in various sectors, 486 were female $(60 \%)$ and 324 male $(40 \%)$. The mean age of the participants was 45.07 years $(\mathrm{SD}=9.26)$. Most participants $(84 \%)$ reported to possess at least a bachelor's degree. Various sectors were represented in the study: health care (18\%), education (18\%), professional services $(12 \%)$, government $(14 \%)$, industry $(13 \%)$, information technology $(17 \%)$, and financial services $(8 \%)$. The questionnaires were identical for all participants, who all voluntary participated in this study.

\subsection{Measures}

Personal Resources. Self-efficacy (Schwarzer \& Jerusalem, 1995) consists of four items, of which an example is: "I am confident that I can deal effectively with unexpected events." Participants had to score the items on a four-point scale, from (1) absolutely wrong to (4) absolutely right. $(\alpha=.79)$. Resilience (Block \& Kremen, 1996) consists of five items, including: "I enjoy dealing with new and unusual situations." Participants had to score the items on a four point scale, from (1) does not apply at all to (4) applies very strongly. ( $\alpha$ $=.75)$.

Job Resources. Performance feedback was assessed using a three-item scale developed by Bakker, Demerouti, Taris, Schaufeli, and Schreurs (2003). A sample item is: "I receive sufficient information about my work objectives." Participants had to score the items on a five-point scale, ranging from (1) never to (5) always. $(\alpha=.87)$. Opportunities for professional development were assessed using three items from Bakker et al.'s (2003) scale. An item is "My work offers me the possibility to learn new things." All items were scored on a five-point scale ranging from (1) totally disagree to (5) totally agree. $(\alpha=.89)$

Perceived Opportunities to Craft (POC) was measured using the five-item scale developed by Van Wingerden and Niks (2017). An example is: "At work I have the opportunity to take on new activities and challenges." Participants had to score the items on a 7-point scale ranging from 1 (totally disagree) to 7 (totally agree). $(\alpha=.91)$.

Job Crafting was measured using 3 subscales of the Job Crafting questionnaire developed by Tims et al. (2012). Each subscale consisted of five items using a five-point scale, ranging from (1) never to (5) very often. Examples are: "I ask colleagues for advice" (increasing social job resources) $(\alpha=.76)$, "When an interesting project comes along, I offer myself proactively as project co-worker" (increasing challenging job demands) $(\alpha=.77)$, and "I try to develop my capabilities" (increasing structural job resources) $(\alpha=.74)$.

\subsection{Analysis}

We tested the proposed model with structural equation modelling (SEM) analyses using AMOS (Arbuckle, 2005). The chi-square, the goodness-of-fit index (GFI), and the root mean square error of approximation (RMSEA) were assessed in order to determine the fit of the model and the alternative models to the data. The incremental fit index (IFI) and the comparative fit index (CFI) were also tested as recommended by Marsh, Balla, and Hau 
(1996). The values of GFI, IFI, CFI > .90 and RMSEA < .08 indicate a reasonable fit of the model to the data (Browne and Cudeck, 1993; Hoyle, 1995). As the use of parcels in structural equation modelling leads to more reliable measurement models (Little, Cunningham, Shahar, \& Widaman, 2002), we conducted our SEM analysis on a partial disaggregation model (Bagozzi \& Edwards, 1998) by creating parcels as recommended by Hall, Snell, and Foust (1999). Parcels of items were created for 'Perceived opportunity to craft', which were included in the model as latent factors with two indicators. 'Job resources', 'Personal resources' and 'Job crafting' were included as latent factors with their aforesaid subscales as the indicators. We examined indirect relationships between job characteristics and job crafting via bootstrapping.

\section{Results}

\subsection{Descriptive Statistics}

An overview consisting of the means, standard deviations, correlations, and reliability coefficients (Cronbach's alpha) of all the relevant demographic variables and model variables can be found in Table 1.

Table 1. Means, Standard Deviations, Correlations, and Reliability Coefficients (Cronbach's Alpha, Diagonal) of all the Demographic Variables and Model Variables $(N=810)$

\begin{tabular}{|c|c|c|c|c|c|c|c|c|c|c|c|c|c|}
\hline & Variables & $M$ & $S D$ & 1. & 2. & 3. & 4. & 5. & 6. & 7. & 8. & 9. & 10. \\
\hline 1. & Gender $^{1}$ & 1.60 & .48 & $(--)$ & & & & & & & & & \\
\hline 2. & Age & 45.07 & 9.26 & $-.14^{* *}$ & $(--)$ & & & & & & & & \\
\hline 3. & $\begin{array}{l}\text { Developmental } \\
\text { Opportunities }\end{array}$ & 3.79 & .85 & -.03 & $.12^{* * *}$ & $(.89)$ & & & & & & & \\
\hline 4. & Feedback & 3.52 & .85 & -.04 & $.11^{* *}$ & $.59^{* *}$ & $(.87)$ & & & & & & \\
\hline 5. & Self-Efficacy & 3.92 & .52 & -.04 & $.08^{*}$ & $.17^{* *}$ & $.23^{* *}$ & $(.79)$ & & & & & \\
\hline 6. & Resilience & 3.94 & .55 & .00 & $.12^{* *}$ & $.19^{* *}$ & $.22^{* *}$ & $.56^{* *}$ & $(.75)$ & & & & \\
\hline 7. & $\begin{array}{l}\text { Perceived Opportunities to } \\
\text { Craft }\end{array}$ & 5.40 & 1.09 & -.03 & $.11^{* *}$ & $.68^{* *}$ & $.51^{* *}$ & $.22^{* *}$ & $.28^{* *}$ & $(.91)$ & & & \\
\hline 8. & $\begin{array}{l}\text { Job Crafting: Structural } \\
\text { Resources }\end{array}$ & 4.26 & .52 & $.10^{* *}$ & .03 & $.41^{* *}$ & $.34^{* *}$ & $.35^{* *}$ & $.39^{* *}$ & $.43^{* *}$ & $(.74)$ & & \\
\hline 9. & $\begin{array}{l}\text { Job Crafting: Social } \\
\text { Resources }\end{array}$ & 3.21 & .71 & $.12^{* *}$ & $-.13^{* *}$ & $.25^{* *}$ & $.35^{* *}$ & $.13^{* *}$ & $.21^{* *}$ & $.29^{* *}$ & $.37^{* *}$ & $(.76)$ & \\
\hline 10. & $\begin{array}{l}\text { Job Crafting: Challenging } \\
\text { Demands }\end{array}$ & 3.89 & .65 & $.09^{*}$ & -.03 & $.27^{* *}$ & $.21^{* *}$ & $.36^{* *}$ & $.49^{* *}$ & $.36^{* *}$ & $.50^{* *}$ & $.35^{* *}$ & $(.77)$ \\
\hline
\end{tabular}

Note. $11=$ male, $2=$ female $; *<.05 ; * * p<.01$.

\subsection{Hypothesis Testing}

Prior to testing our hypotheses, we used SPSS AMOS to test a measurement model in order to verify whether or not our latent model variables were accurately measured by their parcels. The results showed that the measurement had a good fit with the data, $\chi^{2}(21)=132.292, p$ $<.001 ; \mathrm{CFI}=.968 ; \mathrm{TLI}=.945 ; \mathrm{IFI}=.968 ; \mathrm{RMSEA}=.079$ (see Table 2 for an overview of all 
tested models). In addition, all parcels had significant loadings on the intended factors (range $\lambda=.48-.95 ; p<.001)$.

Next, in order to assess whether or not our proposed model would fit our data, we again used SPSS AMOS to conduct a confirmatory factor analysis. The results of the CFA indicated that the model fit of our proposed model was acceptable, $\chi^{2}(21)=132.292, p<.001$; CFI $=.968$; $\mathrm{TLI}=.945$; IFI $=.968$; RMSEA $=.079$. The coefficients of the relations are summarized in Figure 1 . Job resources was positively related to POC $(\beta=.76, p<.001)$, job crafting $(\beta=.26$, $p<.001)$, and personal resources $(\beta=.30, p<.001)$. Personal resources was positively related to $\operatorname{POC}(\beta=.12, p<.001)$, job crafting $(\beta=.56, p<.001)$, and job resources $(\beta=.30, p<.001)$. POC was positively related to job crafting $(\beta=.18, p<.001)$.

We also tested multiple alternative models. First we tested an alternative model, which omitted the direct relations between job resources and job crafting, and between personal resources and POC. The fit of this model was also acceptable, $\chi^{2}(23)=153.700, p<.001$; $\mathrm{CFI}=.963 ;$ TLI $=.941 ; \mathrm{IFI}=.963 ;$ RMSEA $=.081$. However, a subsequent chi-square comparison test showed that the proposed model still had a significantly better fit than the alternative model, $\Delta \chi^{2}(2)=21.408, p<.001$. The second alternative model was a full mediation model beginning at job resources, and subsequently leading to personal resources, POC, and job crafting. This model had a poor fit to the data, $\chi^{2}(24)=588.536, p<.001$; CFI $=.838 ; \mathrm{TLI}=.758 ; \mathrm{IFI}=.839 ; \mathrm{RMSEA}=.165$. The fit was also significantly worse than that of the proposed model, $\Delta \chi^{2}(3)=456.244, p<.001$. The third alternative model was similar to the second alternative model, but included a direct relationship from job resources to job crafting (i.e., a partial mediation model). This model had a poor fit to the data, $\chi^{2}(23)=$ $504.860, p<.001 ; \mathrm{CFI}=.862 ; \mathrm{TLI}=.784 ; \mathrm{IFI}=.863 ; \mathrm{RMSEA}=.156$. The fit was also significantly worse than that of the proposed model, $\Delta \chi^{2}(2)=372.568, p<.001$. Next, we tested two alternative models also starting with job resources, but considering personal resources as a potential outcome of job crafting. The fourth alternative model was a full mediation model starting at job resources, and subsequently leading to POC, job crafting, and personal resources. This model had an acceptable fit to the data, $\chi^{2}(24)=150.498, p<.001$; $\mathrm{CFI}=.964 ; \mathrm{TLI}=.946 ; \mathrm{IFI}=.964 ; \mathrm{RMSEA}=.078$. However, the fit was significantly worse than that of the proposed model, $\Delta \chi^{2}(3)=18.206, p<.001$. The fifth alternative model was a partial mediation model starting at job resources, and subsequently leading to POC, job crafting, and personal resources with a direct relationship between job resources and personal resources. This model had an acceptable fit to the data, $\chi^{2}(23)=145.936, p<.001$; CFI $=.965 ; \mathrm{TLI}=.954 ; \mathrm{IFI}=.965 ; \mathrm{RMSEA}=.079$. However, the fit was significantly worse than that of the proposed model, $\Delta \chi^{2}(2)=13.644, p=.001$.

Further, we tested two additional alternative models starting with personal resources, considering job resources as a potential outcome of perceived opportunities to craft and job crafting behavior. The sixth alternative model was another full mediation model, which started with personal resources, but subsequently led to POC, job crafting, and ending with job resources. This model had a poor fit to the data, $\chi^{2}(24)=476.631, p<.001$; CFI $=.870$; $\mathrm{TLI}=.806 ; \mathrm{IFI}=.871 ; \mathrm{RMSEA}=.148$. The fit was also significantly worse than the proposed model, $\Delta \chi^{2}(3)=344.339, p<.001$. The seventh alternative model was similar to the 


\section{Macrothink}

International Journal of Human Resource Studies

ISSN 2162-3058 2019, Vol. 9, No. 3

sixth alternative model, but included a direct relationship from personal resources to job resources (i.e. a partial mediation model). This model had a poor fit to the data, $\chi^{2}(23)=$ $468.918, p<.001 ; \mathrm{CFI}=.872 ; \mathrm{TLI}=.800 ; \mathrm{IFI}=.873 ; \mathrm{RMSEA}=.150$. The fit was also significantly worse than that of the proposed model, $\Delta \chi^{2}(2)=336.626, p<.001$.

Lastly, we also tested a direct effects model where job crafting was directly predicted by job resources, personal resources, and POC. This model showed a poor fit to the data, $\chi^{2}(24)=$ $760.624, p<.001 ; \mathrm{CFI}=.789 ; \mathrm{TLI}=.684 ; \mathrm{IFI}=.790 ; \mathrm{RMSEA}=.189$. The model fit of the direct effects model was also significantly worse than the fit of the proposed model, $\Delta \chi^{2}(3)=$ $628.332, p<.001$. All in all, we tested multiple alternative models, but the proposed model showed the best fit with the data, thereby confirming our hypotheses.

Table 2. Fit Indices for all Models Tested in the Study, Including Chi-Square Test Results, CFI, TLI, IFI, and RMSEA

\begin{tabular}{lccccccc}
\hline Model & $\chi^{2}$ & $d f$ & $p$ & CFI & TLI & IFI & RMSEA \\
\hline Measurement Model & 132.292 & 21 & $<.001$ & .968 & .945 & .968 & .078 \\
Proposed Model & 132.292 & 21 & $<.001$ & .968 & .945 & .968 & .078 \\
First Alternative Model & 153.700 & 23 & $<.001$ & .963 & .941 & .963 & .081 \\
Second Alternative Model & 588.536 & 24 & $<.001$ & .838 & .754 & .839 & .165 \\
Third Alternative Model & 504.860 & 23 & $<.001$ & .862 & .784 & .863 & .156 \\
Fourth Alternative Model & 150.498 & 23 & $<.001$ & .964 & .946 & .964 & .078 \\
Fifth Alternative Model & 145.936 & 23 & $<.001$ & .965 & .945 & .965 & .079 \\
Sixth Alternative Model & 476.631 & 24 & $<.001$ & .870 & .806 & .871 & .148 \\
Seventh Alternative Model & 468.918 & 23 & $<.001$ & .872 & .800 & .873 & .150 \\
Direct Effects Model & 760.624 & 24 & $<.001$ & .789 & .684 & .790 & .189 \\
\hline
\end{tabular}




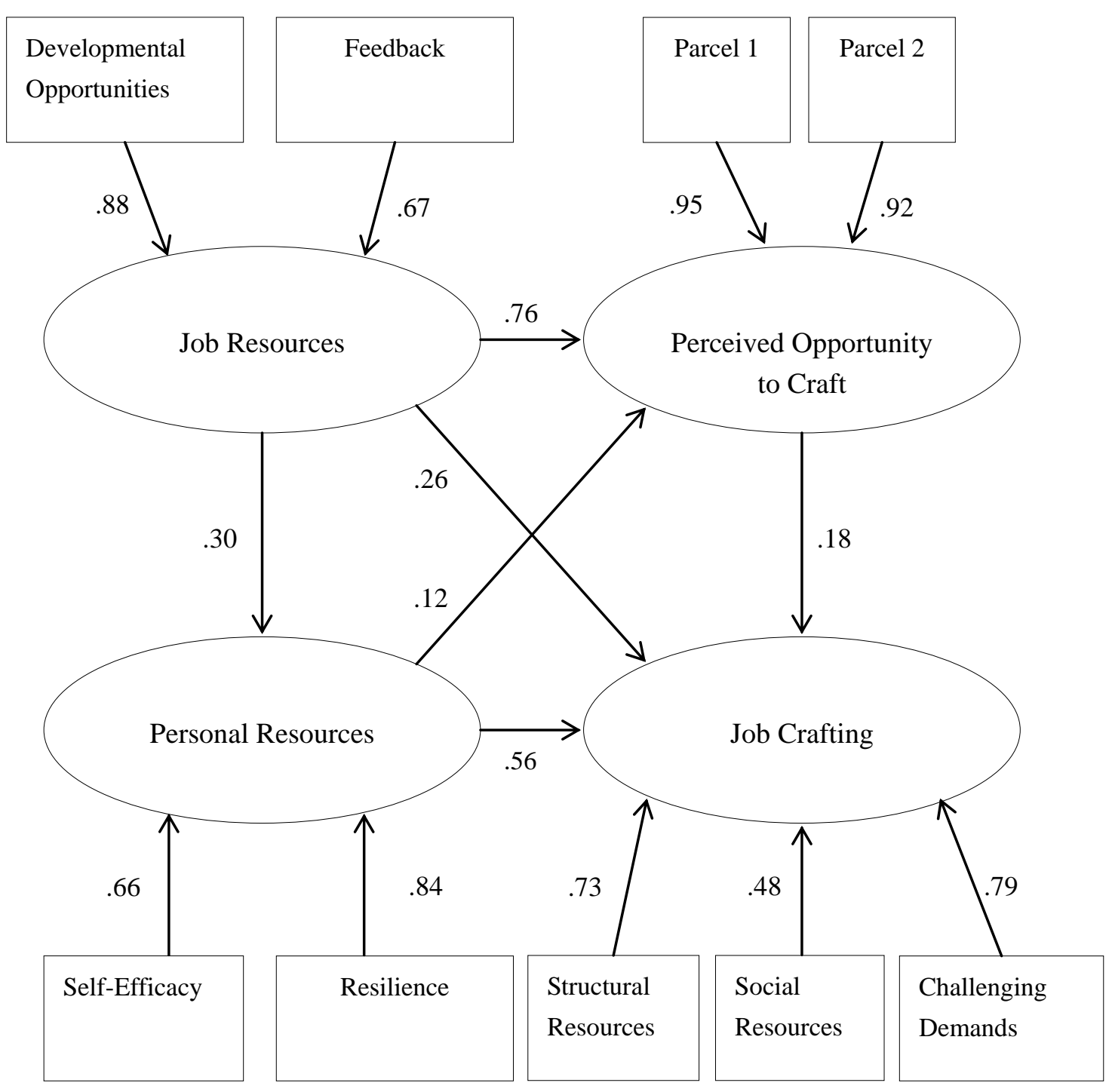

Figure 2. Final Results of the Proposed Model. Including Standardized Coefficients for all Relations

\section{Discussion}

In this study we have constructed and tested a model of job crafting antecedents including employee perceptions (perceived opportunities to craft), employee characteristics (resilience and self-efficacy as personal resources), and work characteristics (performance feedback and developmental opportunities as job resources). We have argued that job crafting behavior may be influenced by the interplay between job resources, personal resources, and perceived opportunities to craft. Although earlier research had revealed that job crafting is beneficial for both employees and employers (Leana, Appelbaum, \& Shevchuk, 2009; Petrou et al., 2012; Van Wingerden et al., 2017a), up till now little was known about how both job resources and personal resources co-influence job crafting perceptions and job crafting behaviors. Results of the present study demonstrate that job resources are related to job crafting behavior in multiple and interrelated ways; via perceived opportunities to craft, via personal resources, and via personal resources affecting perceived opportunities to craft. This study supports our 
proposed model, which accounts for these different pathways, which in combination predicted job crafting behavior the best, implying that multiple factors and processes simultaneously precede job crafting behavior at work.

\subsection{Theoretical Contributions}

This study contributes to the job crafting literature by exploring and testing how job crafting perceptions and behaviors are influenced by job resources and personal resources. In earlier studies, the inclusion of personal resources in JD-R theory has been recognized as an important extension of the original framework (Bakker et al., 2014). The outcomes of our study underline the importance of personal resources, especially in relation to understanding proactive employee behavior. Other studies have linked job characteristics to employees' perceived opportunities to craft and job crafting behavior (e.g., Van Wingerden \& Niks, 2017; Van Wingerden \& Poell, 2018), while other researchers have linked personal characteristics to employees' job crafting behavior (e.g., Bipp \& Demerouti, 2015; Gordon, et al., 2015). Despite all those studies, the precise interactions between these predictors and how they impact job crafting behavior, remained unclear. We have presented in the current study a framework to model the processes preceding job crafting, while controlling for other possible pathways. In our analysis we compared the proposed model with eight alternative models, which clearly demonstrated that the proposed model constituted the best fit with the data. This study has thus provided evidence for the proposed model of job crafting antecedents.

\subsection{Limitations and Suggestions for Future Research}

Although this study provides ample evidence for the proposed model, there are also some limitations that need to be acknowledged. A first limitation of this study is related to the study design, which is cross-sectional and non-experimental. Based on the current design, we cannot prove causality between the variables within this study. Although we tested eight alternative models compared to our proposed model and the outcomes revealed the best model fit for the proposed model, other types of study designs are required to determine strong causality. Thus, to examine causality among job resources, personal resources, perceived opportunities to craft, and job crafting behavior, future studies should replicate this study using research designs such as diary and/or longitudinal studies. These types of studies may provide insights into how these constructs are related over time.

Second, data within this study was gathered among Dutch employees who work in different industries and organizations. Also, the participants within this study are mostly highly educated. This may limit the generalizability of this study, because we do not know if we would find similar relationships in other cultures or among employees with other education levels. Therefore, future research is needed to test the antecedents of our job crafting model among employees working in other countries and with other educational backgrounds as well.

A third limitation of this study is related to the self-report nature of our data. By using self-reports we cannot evade common method bias, which may inflate the correlations among the different variables within this study. However, according to Sousa-Poza and Sousa-Poza 
(2000), employees' self-evaluations may be the best method to capture perceptions and feelings related to their work environment and well-being, especially because they are subjective. Nevertheless, the results of this study should be interpreted with care and future research might explore additional, more objective ways to measure the variables used in this study (Podsakoff, MacKenzie, Lee, \& Podsakoff, 2013), for example, by measuring supervisor and/or peer ratings of job crafting behavior.

In this study we focused on three types of antecedents of job crafting behavior. Future studies may also examine other types of variables that could complement the framework of job crafting antecedents. For example, alternative job resources like team cohesion (e.g. Chang \& Bordia, 2001) or autonomy (e.g. Bakker, Demerouti, \& Verbeke, 2004), might be interrelated with perceived opportunities to craft, personal resources, and thus subsequently job crafting behavior. Likewise, alternative personal resources, like optimism (e.g. Luthans, et al., 2007) or employee personality (e.g. Bakker, Boyd, Dollard, Gillespie, Winefield, \& Stough, 2010; Bakker, et al., 2012) might be interesting avenues for future research.

\subsection{Practical Implications and Conclusion}

Gaining a better understanding of these antecedents of job crafting behavior has its practical implications as well. As the outcomes of this study have revealed, both elements of the work environment (job resources) and aspects of the self (personal resources) influence employees' job crafting perceptions, and subsequently their job crafting behavior. Organizations that want to stimulate job crafting among their employees may facilitate employees with a sufficient amount of job resources and opportunities to optimize their work environment. At the same time, these organizations may consider to empower employees and support them in enhancing their self-efficacy and resilience.

In order to stimulate and achieve these objectives, organizations can use surveys to examine how employees experience their work environment, their job resources, and their personal resources. Offering all employees a personalized feedback report based on this survey may create more awareness about the work environment and about opportunities to optimize the fit between the employees' job and their individual talents, interests, and passions. Conversations between employees and their supervisors about the outcomes of the survey may further help to better understand the idiosyncratic factors that influence job crafting behavior of the employee. Based on the outcomes of these surveys and the conversations between employees and their supervisors, organizations can learn how to build and/or strengthen a resourceful organizational climate that supports employees in proactively aligning their work environment with their talents, strengths, and interests.

The positive relationships found in the current study provide HR and senior management with insights that can help improve their human resources policies. For example, contemporary organizations that want to facilitate optimal conditions for job crafting behavior may offer their employees a wide range of human resource development activities, such as training and coaching, in order to strengthen their personal resources. Organizations can also offer their employees opportunities to participate in job crafting training interventions, by which employees can experience how job crafting can be a useful skill for 
them during their career. Research has revealed that offering these types of interventions turned out to be worthwhile, since they are effective in increasing job crafting behavior, work engagement, and performance (Gordon, 2015; Van den Heuvel, Demerouti, \& Peeters, 2012; Van Wingerden et al., 2017a; Van Wingerden et al., 2017b; Van Wingerden et al., 2013). Also, job crafting intervention effects turned out to be sustainable over time (Van Wingerden et al., 2017b).

In conclusion, this study has presented a comprehensive framework of job crafting antecedents. While extant research has previously identified multiple antecedents of job crafting (e.g. Van Wingerden, Derks, Bakker, \& Dorenbosch, 2013; Van Wingerden \& Poell, 2017), no study - as far as we know- have addressed these antecedents in one overarching model and have researched their combined impact on job crafting behavior. We hope that this framework will help scholars to better conceptualize and position their work on job crafting behavior, and may help practitioners to further stimulate job crafting behavior and subsequently engagement and performance within contemporary organizations

\section{Funding}

This research received no specific grant from any organization or funding agency.

\section{References}

Arbuckle, J. L. (2005). Amos 6.0 User's Guide. Chicago, IL: SPSS, Inc.

Ashford, S. J., Blatt, R., \& Vande, W. D. (2003). Reflections on the looking glass: A review of research on feedback-seeking behavior in organizations. Journal of Management, 29, 773-799. http://dx.doi.org/10.1016/S0149-2063(03)00079-5

Australian academic staff. Career Development International, 15, 622-636. http://dx.doi.org/10.1108/13620431011094050

Bagozzi, R. P., \& Edwards, J. R. (1998). A general approach for representing constructs in organizational research. Organizational Research Methods, 1, 45-87. http://dx.doi.org/10.1177/109442819800100104

Bakker, A. B., \& Bal, M. P. (2010). Weekly work engagement and performance: A study among starting teachers. Journal of Occupational and Organizational Psychology, 83(1), 189-206. http://dx.doi.org/10.1348/096317909X402596

Bakker, A. B., \& Demerouti, E. (2014). Job demands-resources theory. In C. Cooper and https://doi.org/10.1002/9781118539415.wbwell019

Bakker, A. B., Boyd, C. M., Dollard, M., Gillespie, N., Winefield, A. H., \& Stough, C. (2010). The role of personality in the job demands-resources model: A study of

Bakker, A. B., Demerouti, E., \& Sanz-Vergel, A. I. (2014). Burnout and work engagement: The JD-R approach. Annual Review of Organizational Psychology and Organizational Behavior, 1(1), 389-411. http://dx.doi.org/10.1146/annurev-orgpsych-031413-091235 
Bakker, A. B., Demerouti, E., Taris, T. W., Schaufeli, W. B., \& Schreurs, P. J. G. (2003). A multi-group analysis of the Job Demands-Resources model in four home care organizations. International Journal of Stress Management, 10, 16-38.

Bakker, A. B., Demerouti, E., Verbeke, W. (2004). Using the job demands-resources model to predict burnout and performance. Human Resource Management, 43, 83-104. http://dx.doi.org/10.1002/hrm.20004

Bakker, A. B., Tims, M., \& Derks, D. (2012). Proactive personality and job performance: The role of job crafting and work engagement. Human Relations, 65, 1359-1378. http://dx.doi.org/10.1177/0018726712453471

Bandura, A. (1977). Self-efficacy: toward a unifying theory of behavioral change. Psychological review, 84(2), 191-215. http://dx.doi.org/10.1037/0033-295X.84.2.191

Bandura, A. (1982). Self-efficacy mechanisms in human agency. American Psychologist, 37, 122-147. http://dx.doi.org/10.1037/0003-066X.37.2.122

Bandura, A. (1996). Social learning theory. Englewood Cliffs, NJ: Prentice-Hall.

Bipp, T., \& Demerouti, E. (2015). Which employees craft their jobs and how? Basic dimensions of personality and employees' job crafting behavior. Journal of Occupational and Organizational Psychology, 88, 631-655.

Block, J., \& Kremen, A. M. (1996), IQ and ego-resiliency: Conceptual and empirical connections and separateness, Journal of Personality and Social Psychology, 70, 349-361.

Boyd, C. M., Bakker, A. B., Pignata, S., Winefield, A. H., Gillespie, N. and Stough, C. (2011). A longitudinal test of the Job Demands-Resources model among Australian university academics. Applied Psychology: An International Review, 60, 112-140. http://dx.doi.org/10.1111/j.1464-0597.2010.00429.x

Brenninkmeijer, V., \& Hekkert-Koning, M. (2015). To craft or not to craft: The relationships between regulatory focus, job crafting and work outcomes. Career Development International, 20, 147-162. http://dx.doi.org/10.1108/CDI-12-2014-0162

Browne, M. W., \& Cudeck, R. (1993). Alternative ways of assessing model fit. In K. A. Bollen and J. S. Long (Eds.), Testing structural equation models (pp. 445-455). Newbury Park, CA: Sage.

Chang, A., \& Bordia, P. (2001). A multidimensional approach to the group cohesion-group performance relationship. Small Group Research, 32, 379-405. http://dx.doi.org/10.1177/104649640103200401

Chen, P. (Eds.), Wellbeing: A complete reference guide (pp. 37-64). Chichester, UK: Wiley-Blackwell.

Colbert, J. A., Brown, R. S., Choi, S., \& Thomas, S. (2008). An investigation of the impacts of teacher-driven professional development on pedagogy and student learning. Teacher Education Quarterly, 35(2), 135-154. 
commentary. Journal of Occupational and Organizational Psychology, 87(1), 34-41. http://dx.doi.org/10.1111/joop.12048

Demerouti, E., \& Rispens, S. (2014). Improving the image of student-recruited samples: A

Demerouti, E., Bakker, A. B., Nachreiner, F., \& Schaufeli, W. B. (2001). The job demands-resources model of burnout. Journal of Applied psychology, 86(3), 499. http://dx.doi.org/10.1037/0021-9010.86.3.499

Ghitulescu, B. E. (2007). Shaping tasks and relationships at work: Examining the antecedents and consequences of employee job crafting (Doctoral dissertation, University of Pittsburgh).

Gist, M. E., \& Mitchell, T. R. (1992). Self-efficacy: A theoretical analysis of its determinants and malleability. Academy of Management Review, 17, 183-211.

Gordon, H. J., Demerouti, E., Le Blanc, P. M., \& Bipp, T. (2015). Job crafting and performance of Dutch and American health care professionals. Journal of Personnel Psychology, 14, 192-202. http://dx.doi.org/10.1027/1866-5888/a000138

Hakanen, J., Bakker, A. B. and Schaufeli, W. B. (2006). Burnout and work engagement among teachers, Journal of School Psychology, 43, 495-513. http://dx.doi.org/10.1016/j.jsp.2005.11.001

Hall, R. J., Snell, A. F., \& Foust M. (1999). Item parceling strategies in SEM: Investigating the subtle effects of unmodeled secondary constructs. Organizational Research Methods, 2, 233-256. http://dx.doi.org/10.1177/109442819923002

Hobfoll, S. E., Johnson, R. J. Ennis, N., \& Jackson, A. P. (2003). Resource loss, resource gain, and emotional outcomes among inner city woman. Journal of Personality and Social Psychology, 84, 632-643.

Hoyle, R. H. (1995). Structural equation modeling: Concepts, issues, and applications. Thousand Oaks, CA: Sage.

James, L. A., \& James, L. R. (1989). Integrating work environment perspectives: Explorations into the measurement of meaning. Journal of Applied Psychology, 74, 739-751.

Leana, C., Appelbaum, E., \& Shevchuk, I. (2009). Work process and quality of care in early childhood education: The role of job crafting. Academy of Management Journal, 52, 1169-1192. https://doi.org/10.5465/amj.2009.47084651

LePine, J. A., \& Van Dyne, L. (1998). Helping and Voice Extra-Role Behaviors: Evidence of Construct and Predictive Validity. The Academy of Management Journal, 41(1), 108-119.

Little, T. D., Cunningham, W. A., Shahar, G., \& Widaman, K. F. (2002). To parcel or not to parcel: Exploring the question, weighing the merits. Structural Equation Modeling, 9, 151-173. http://dx.doi.org/10.1207/S15328007SEM0902_1 


\section{Macrothink}

International Journal of Human Resource Studies

ISSN 2162-3058

2019, Vol. 9, No. 3

Luthans, F. (2002). The need for and meaning of positive organizational behavior. Journal of Organizational Behavior, 23, 695-706. http://dx.doi.org/10.1002/job.165

Luthans, F. Y., Youssef, C. M., \& Avolio, B. J. (2007). Psychology capital: Developing the human competitive edge. New York: Oxford University Press.

Luthans, F., \& Youssef, C. M. (2007). Emerging positive organizational behavior. Journal of Management, 33, 321-349. http://dx.doi.org/10.1177/0149206307300814

MacKinnon, D. P. (2008). Introduction to statistical mediation analysis. London: Routledge.

Marsh, H. W., Balla, J. R., \& Hau, K. T. (1996). An evaluation of incremental fit indices: A clarification of mathematical and empirical properties. Advanced structural equation modeling: Issues and techniques, 315-353.

Masten, A. S. (2001). Ordinary magic: Resilience processes in development. American Psychologist, 56, 227-239. http://dx.doi.org/10.1037/0003-066X.56.3.227

Petrou, P., Demerouti, E., Peeters, M. C. W., Schaufeli, W. B., \& Hetland, J. (2012). Crafting a job on a daily basis: Contextual correlates and the link to work engagement. Journal of Organizational Behavior, 33, 1120-1141. http://dx.doi.org/10.1002/job.1783

Podsakoff, P. M., MacKenzie, S. B., Lee., J., \& Podsakoff, N. P. (2003). Common method bias in behavioral research: A critical review of the literature and recommended remedies. Journal of Applied Psychology, 88, 879-903. http://dx.doi.org/10.1037/0021-9010.88.5.879

Reichers, A. E., \& Schneider, B. (1990). Organizational climate and culture. Climate and culture: An evolution of constructs, 5-39.

Schneider, B., \& Reichers, A. E. (1983). On the etiology of climates. Personnel psychology, 36(1), 19-39. http://dx.doi.org/10.1111/j.1744-6570.1983.tb00500.x

Schwarzer, R., \& Jerusalem, M. (1995). Generalized self-efficacy scale. In J. Weinman, S. Wright, \& M. Johnston, Measures in health psychology: A user's portfolio. Causal and control beliefs (pp. 35-37). Windsor, UK: NFER-NELSON.

Sousa-Poza, A., \& Sousa-Poza, A. A. (2000). Well-being at work: A cross-sectional study of the levels and determinants of job satisfaction. Journal of Socio-Economics, 29, 517-538. https://doi.org/10.1016/S1053-5357(00)00085-8

Tims, M., Bakker, A. B., \& Derks, D. (2012). Development and validation of the job crafting $\begin{array}{lllll}\text { scale. Journal of Vocational } & \text { Behavior, } & 80, & 173-186 .\end{array}$ http://dx.doi.org/10.1016/j.jvb.2011.05.009

Tims, M., Bakker, A. B., Derks, D., and Van Rhenen, W. (2013). Job crafting at the team and individual level: Implications for work engagement and performance. Group and Organization Management, 38, 427-454. http://dx.doi.org/10.1177/1059601113492421

Van den Broeck, A., Vansteenkiste, M., De Witte, H., \& Lens, W. (2008). Explaining the relationships between job characteristics, burnout, and engagement: The role of basic 


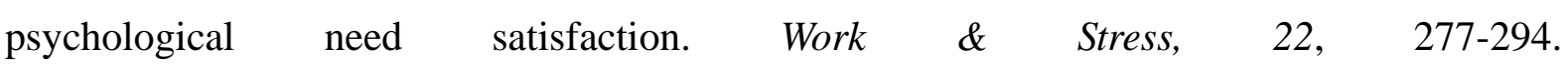
http://dx.doi.org/10.1080/02678370802393672

Van den Broeck, A., Vansteenkiste, M., De Witte, H., Soenens, B., \& Lens, W. (2010). Capturing autonomy, competence, and relatedness at work: Construction and initial validation of the Work-related Basic Need satisfaction scale. Journal of Occupational and Organizational Psychology, 83, 981-1002. http://dx.doi.org/10.1348/096317909X481382

Van den Heuvel, M., Demerouti, E., \& Peeters, M. (2012). Succesvol job craften door middel van een groepstraining. [Succesful job crafting by training in groups]. Scherp in werk, 5, 27-49.

van Wingerden, J., \& Niks, I. (2017). Construction and validation of the Perceived Opportunity to Craft Scale. Frontiers in Psychology, 8, 573. http://dx.doi.org/10.3389/fpsyg.2017.00573

van Wingerden, J., \& Poell, R. F. (2017). Employees' perceived opportunities to craft and in-role performance: The mediating role of job crafting and work engagement. Frontiers in Psychology, 8: 1876. http://dx.doi.org/10.3389/fpsyg.2017.01876

Van Wingerden, J., \& Poell, R. F. (2018). Employees' job characteristics and job crafting behavior: The mediating role of perceived opportunities to craft. Frontiers in Psychology. http://dx.doi.org/10.5296/ijhrs.v8i4.13764

van Wingerden, J., Bakker, A. B., \& Derks, D. (2017a). Fostering employee well-being via a job crafting intervention. Journal of Vocational Behavior, 100, 164-174. http://dx.doi.org/10.1016/j.jvb.2017.03.008

van Wingerden, J., Bakker, A. B., \& Derks, D. (2017b). The longitudinal impact of a job crafting intervention. European Journal of Work and Organizational Psychology, 26, 107-119. http://dx.doi.org/10.1080/1359432X.2016.1224233

van Wingerden, J., Bakker, A. B., \& Derks, D. (2017c). The impact of personal resources and job crafting interventions on work engagement and performance. Human Resource Management, 56, 51-67. http://dx.doi.org/10.1002/hrm.21758

Van Wingerden, J., Derks, D., Bakker, A. B., \& Dorenbosch, L. (2013). Job crafting in het speciaal onderwijs: een kwalitatieve analyse [Job crafting in special education: A qualitative analysis]. Gedrag \& Organisatie, 26, 85-103.

Van Wingerden, J., Van der Stoep, J., \& Poell, R. F. (2018). Meaningful work and work engagement: The mediating role of perceived opportunity to craft and job crafting behavior. International Journal of Human Resources Studies. http://dx.doi.org/10.5296/ijhrs.v8i2.12635

Van Wingerden, J., Van Kessel, J., Bakker, A. B., \& Derks, D. (2014). Bevlogen in het onderwijs.[Work engagement in the educational field]. Gouda, Nederland: Anders Ontwikkelen. 


\section{Macrothink}

International Journal of Human Resource Studies

ISSN 2162-3058 2019, Vol. 9, No. 3

Wrzesniewski, A. (2003). Finding positive meaning in work. In K. S. Cameron, J. E. Dutton,\& R. E. Quinn (Eds.), Positive organizational scholarship: Foundations of a new discipline (pp. 298-308). San Francisco, CA: Berrett-Koehler.

Wrzesniewski, A., \& Dutton, J. E. (2001). Crafting a job: Revisioning employees as active crafters of their work. Academy of Management Review, 26, 179-201. http://dx.doi.org/10.5465/amr.2001.4378011

Xanthopoulou, D., Bakker, A. B., Demerouti, E., \& Schaufeli, W. B. (2009). Reciprocal relationships between job resources, personal resources, and work engagement. Journal of Vocational Behavior, 74, 235-244. http://dx.doi.org/10.1016/j.jvb.2008.11.003

Xanthopoulou, D., Bakker, A. B., Demerouti, E., \& Schaufeli, W. B. (2007). The role of personal resources in the job demands-resources model. International Journal of Stress Management, 14, 121-141. http://dx.doi.org/10.1037/1072-5245.14.2.121

\section{Copyright Disclaimer}

Copyright for this article is retained by the author(s), with first publication rights granted to the journal.

This is an open-access article distributed under the terms and conditions of the Creative Commons Attribution license (http://creativecommons.org/licenses/by/4.0/). 